\title{
PAPEL SOCIAL DOS ALGORITMOS: UMA ANÁLISE DOS ESTUDOS ACADÊMICOS ACERCA DOS ALGORITMOS E SUA FUNÇÃO SOCIAL
}

\author{
SOCIAL ROLE OF ALGORITHMS: AN ANALYSIS OF \\ ACADEMIC STUDIES ABOUT THE DIGITAL \\ ALGORITHMS SUCH AS SOCIAL CONCERN
}

Natasha Duarte Amarantea

Jackson da Silva Medeiros ${ }^{b}$

\begin{abstract}
RESUMO
Objetivo: analisar como se constituem os estudos acadêmicos, apresentados em artigos científicos, acerca dos algoritmos digitais como preocupação social, nas áreas de Ciências Sociais e Humanas, através das bases de dados Project Muse, SCOPUS e SciELO. Metodologia: De caráter exploratório e abordagem qualitativa, utiliza os procedimentos metodológicos da Análise de Conteúdo. Resultados: Analisa os 220 artigos científicos selecionados, que trazem em seu conteúdo reflexões acerca do papel social dos algoritmos. Classifica em 11 categorias os artigos analisados, agrupados por semelhança temática. Conclusões: Conclui que a temática com maior representação está relacionada à personalização algorítmica, juntamente com reflexões sobre opacidade, manipulação e discriminação algorítmica, seus impactos e influência no comportamento humano. Compreende que os algoritmos não são neutros, mas refletem e reproduzem as formações discursivas de cada sociedade. Entende que as reflexões e questionamentos acerca do papel social dos algoritmos ainda carecem de pesquisas. Anuncia perspectivas para novos estudos a partir dos resultados e investigações presentes nesta pesquisa.
\end{abstract}

Descritores: Algoritmos. Análise de conteúdo. Regimes de verdade. Regimes de informação. Sociedade de controle.

\section{CONTEXTUALIZAÇÃO DA PESQUISA: ABORDAGENS SOBRE} INFORMAÇÃO, PODER E ALGORITMOS

As tecnologias desenvolvidas alteram e são alteradas conforme as

\footnotetext{
a Mestre em Ciência da Informação pela Universidade Federal do Rio Grande do Sul (UFRGS). Chefe da Equipe de Protocolo e Arquivo Municipal na Divisão de Gestão do Documental da Prefeitura de Porto Alegre. E-mail: natasha.damarante@gmail.com.

b Doutor em Comunicação e Informação pela Universidade Federal do Rio Grande do Sul (UFRGS). Docente do Departamento de Ciências da Universidade Federal do Rio Grande do Sul (UFRGS). E-mail: jackson.medeiros@ufrgs.br.
} 
relações de poder e verdade que cada grupo social possui. Nas sociedades contemporâneas o desenvolvimento da computação e da internet, com a frequente utilização de algoritmos para tomadas de decisões, vêm interferindo nas relações humanas e consequentemente nos regimes de verdade $\mathrm{e}$ informação. À vista disso, cabe às Ciências Sociais Aplicadas e as Ciências Humanas observar e questionar quais são os mecanismos desses algoritmos, quais critérios de amostragem e de apagamento e as suas relações com os regimes de verdade e de informação.

Fruto da dissertação de mestrado apresentada no Programa de PósGraduação em Ciência da Informação da Universidade Federal do Rio Grande do Sul, este trabalho de caráter exploratório e abordagem qualitativa busca analisar como estão constituídos os estudos acadêmicos, apresentados em artigos científicos, acerca dos algoritmos digitais como preocupação social ${ }^{1}$, nas áreas de Ciências Sociais e Humanas, através das bases de dados Project Muse, SCOPUS e SciELO.

As tecnologias influenciam e são influenciadas pelas relações de poder, verdade e informação, tornando-se necessária a reflexão quanto a essas relações. Portanto, antes de adentrarmos nas discussões sobre como os estudos acadêmicos abordam a função social dos algoritmos, para contextualizar nossa pesquisa, apresentamos nos próximos parágrafos reflexões acerca dos mecanismos de poder e produção da verdade para então discorrer sobre a influência dos algoritmos nas nossas escolhas, privacidade e relações sociais.

Michel Foucault (1996), preocupando-se em compreender as relações entre o saber, a verdade e as vontades da verdade, expõe que a verdade segue uma ordem de propósitos, instituições e disciplinas que são subservientes à ordem discursiva dominante. Logo, todo grupo social, independentemente de sua constituição, tem seu modo de produção, compartilhamento e validação da verdade; não se trata de uma verdade absoluta, mas daquilo que é aceito como verdade por uma determinada sociedade e seus mecanismos de validação que

\footnotetext{
1 Expressão utilizada por Tarleton Gillespie e Nick Seaver no site Social Media Collective (SMC), uma rede de pesquisadores de Ciências Sociais e Humanas que tem como objetivo fomentar a pesquisa a respeito da dinâmica social e cultural que sustenta as tecnologias digitais. https://socialmediacollective.org/reading-lists/critical-algorithm-studies/
} 
permitem que esses sejam aceitos como tal. Bert (2013) explica que a partir de "A ordem do discurso" fica mais evidente a preocupação de Foucault sobre a construção da verdade e sua relação com o poder, pois, em sua maioria, o poder dominante detém os dispositivos ${ }^{2}$ de regulamentação do que é aceito como verdade e como seu regime é constituído. Nesse sentido, poder e verdade são intrínsecos.

É importante salientar que Foucault não trata o poder como uma entidade única e estável, mas que ocorre a partir de relações circulares, influenciando e sendo influenciadas por condições históricas e sociais, possuindo constantes e variáveis de acordo com a complexidade de cada sociedade (REVEL, 2005). Foucault (2006) explica que as relações de poder são relações de força e enfrentamentos, sendo, portanto, reversíveis. Desta forma, as relações de poder estão presentes em diversos campos, como nas relações humanas, familiares, escolares, nas relações de trabalho, em relações de Estado e agora através dos algoritmos.

Percebemos então, que existem diversas formas de relações de poder, dentre elas o controle e a delimitação da verdade, onde os discursos acolhidos como verdadeiros obedecem a limites e a critérios estabelecidos, estando sujeitos às necessidades políticas e econômicas das hegemonias, o que vem a ser chamado por Foucault de regime de verdade ${ }^{3}$. Não existe verdade sem poder, logo os regimes de verdade são constituídos de poder, sendo diretamente

\footnotetext{
2 Para este estudo, o entendimento sobre dispositivos vai além do meio, do aparato eletrônico, uma vez que compreende e permite "[...] enxergar o campo social com perspectiva espaçotemporal, isto é, contextualizada através de sua perspectiva institucionalizante e institucionalizada em que as ligações formam o coletivo, ilustrando as vias que esses ocupam. Os dispositivos se constituem, na realidade, como as próprias regulações de critérios que devem ser vistos como verdadeiros. [...] As ações que são instauradas pelos dispositivos não podem ser consideradas ao acaso, por eventualidades, mas devem ser pensadas pela razão justificada do regime de verdade. Constituir uma nova ordem das coisas é criar um novo regime que esteja validado e reconhecido pelo regime atual. Há de se passar por uma alteração de sentidos daqueles que cercam o regime para que o novo seja o atual." (MEDEIROS, 2017, p. 167-174).

${ }^{3}$ A relação de discurso e verdade e a forma como são validados e reproduzidos através de normas pré-estabelecidas, pois "Cada sociedade tem seu regime de verdade, sua 'política geral' de verdade: isto é, os tipos de discurso que ela acolhe e faz funcionar como verdadeiros; os mecanismos e as instâncias que permitem distinguir os enunciados verdadeiros dos falsos, a maneira como se sanciona uns e outros; as técnicas e os procedimentos que são valorizados para a obtenção da verdade; o estatuto daqueles que têm o encargo de dizer o que funciona como verdadeiro." (FOUCAULT, 1979, p. 12).
} 
influenciados por interesses políticos e econômicos. Consequentemente, a informação e suas formas de produção e validação também.

O modo como a informação é produzida, compartilhada, validada e consumida é objeto de estudo da Ciência da Informação, que, fundamentada na percepção do regime de verdade de Foucault, chega à ideia de regimes de informação. Para Frohmann (1995) é extremamente complexo conceituar regimes de informação devido a sua estrutura híbrida constituída por diversos grupos sociais, dispositivos e formações discursivas. Tal complexidade relaciona regimes de informação às relações poder. González de Gómez (1999) qualifica regimes de informação como o modo de produção dominante em uma formação social, composto por vários dispositivos de informação que regulamentam, organizam e padronizam as informações.

As mudanças tecnológicas na sociedade contemporânea possibilitam que o mundo digital se torne cada vez mais real, modificando as relações de poder e, por consequência, os regimes de verdade e informação. Nesse bojo capitalista-tecnológico surgem grandes empresas como o Google e o Facebook, as quais acabam por centralizar as informações da rede, fazendo com que a maioria dos sistemas de informação, plataformas de aplicações e demais empresas de comunicação e informação dependam de suas ferramentas. No entanto, essas empresas são instituições privadas, com suas regras e interesses particulares, ocasionando em uma eventual privatização dos processos informacionais, assim como alertado por Striphas (2015), quando afirma que as empresas estão tornando-se "apóstolos culturais" e informacionais.

$\mathrm{Na}$ sociedade contemporânea o poder agora é algorítmico, com dispositivos responsáveis pela mediação entre usuários e os conteúdos da internet, influenciando e sendo influenciadas pelos novos regimes de verdade e regimes de informação (FOUCAULT, 1979; GILLESPIE, 2017).

Para entender a correspondência entre algoritmo e relações de poder é importante entender que são os algoritmos. Hoje relacionados aos softwares e aos aparatos eletrônicos, são, segundo Gleick (2012), uma nova nomenclatura para algo que sempre existiu, um conjunto de instruções, procedimentos, orientações específicas e organizadas. Cormen (2014) explica que executamos 
algoritmos ao realizarmos tarefas diárias, como escovar os dentes, utilizarmos o transporte público para ir ao trabalho, entre outras incumbências da vida cotidiana. A diferença entre os algoritmos que nós executamos para os procedimentos matemáticos e computacionais está na precisão dessas instruções.

A função primordial do algoritmo é encontrar a solução para problemas através de comandos e parâmetros indicados. Mediante coleta, processamento e mineração de dados, o algoritmo processa e reconhece padrões, categorizando dados desconhecidos, ajustando parâmetros e disponibilizando respostas que os humanos não conseguiriam encontrar ou demorariam muito para fazer (OLIVEIRA, 2018). Entretanto, para que os algoritmos encontrem padrões significativos, é necessário ter dados suficientes. Para Gillespie (2018, p. 98), "[...] algoritmos são máquinas inertes e sem sentido até serem combinados com bancos de dados para com eles funcionar". Os bancos de dados são formados por dados fornecidos por nós, nosso rastro digital, como os sites que acessamos, pesquisas que respondemos, transações bancárias, entre outros.

Esse conjunto de informações que disponibilizamos dão ao algoritmo a possibilidade de identificar padrões, aprender e fazer inferências sobre nós. Esses dados são insumo e produto do novo capitalismo, utilizados pelas empresas e governos. As informações são utilizadas como forma de conhecer nossos gostos, preferências, bens, estilo, posição política, entre outros, para que então seja traçado nosso perfil e, a partir daí, sejam desenvolvidos algoritmos capazes de regular nossos acessos e nossas escolhas (PARISER, 2012). Por mais que as máquinas pareçam autônomas, Gillespie $(2018$, p. 98) alerta que não devemos "[...] conceber os algoritmos como realizações técnicas abstratas, mas desvendar as escolhas humanas e institucionais que estão por trás desses mecanismos frios". É importante compreendermos que um algoritmo para computadores, apesar de utilizar parâmetros e lógicas, é um produto de seu contexto social.

Os algoritmos, de acordo com Pasquale (2015), podem determinar, pelo menos em parte, nossas formas de lidar com o conhecimento e com a 
informação. A personalização através dos algoritmos, denominada por Striphas de "cultura algorítmica", pode ser compreendida em Pariser (2012, p. 11) como um mecanismo que tem por objetivo prever, criar e refinar quem somos, o que faremos e o que desejamos, criando um universo exclusivo de informação para cada usuário, denominada pelo autor de "bolha dos filtros".

Como instrumento de controle social, fruto de um contexto com relações de dominância de poder, as inferências feitas pelos algoritmos, com base nos bancos de dados, seguem a (re)produção de comportamentos de uma sociedade. Além de categorizar, classificar e personalizar dados, os algoritmos recebem comandos, exemplos e correlacionam milhares de dados, para então construir suas próprias instruções e códigos. Com aparente objetividade e racionalidade, juntamente com a falta de compreensão do funcionamento dos sistemas algorítmicos por parte dos usuários, os resultados de busca da internet, por exemplo, podem estar carregados de subjetividade e vieses discriminatórios (CARRERA, 2020).

Os algoritmos e linguagens de programação, a coleta e armazenamento dos dados digitais, além de lógica e controle, contêm implicações políticas, sociais e econômicas, servindo em sua maioria a um grupo dominante que regula os regimes de informação. Vivemos um novo capitalismo, diferente do capitalismo mercantil, industrial ou até mesmo o capitalismo liberal. $O$ neoliberalismo ${ }^{4}$ tem implicações diretas no desenvolvimento das tecnologias, principalmente a internet que, diferentemente das sociedades disciplinares e da biopolítica apresentadas por Foucault, busca a modulação comportamental por meio de concorrência e produtividade.

Com destaque a partir do neoliberalismo, as relações de poder se estabelecem através de controle virtual, tanto do indivíduo, quanto da população, indo ao encontro do que Deleuze (1992) caracteriza como sociedade de controle. Nas sociedades de controle, o que está sendo manejado não são apenas os indivíduos e seus corpos, mas também fluxos e ideias através de modulações,

\footnotetext{
${ }^{4}$ Em nosso estudo, e pelo espaço disponível para cobrir os assuntos relevantes do trabalho, não discorremos sobre o neoliberalismo. Uma introdução e compreensão do seu modo de atuação na sociedade e na formação do sujeito, pode ser encontrada em Dardot e Laval (2016), no livro A nova razão do mundo.
} 
"[...] uma moldagem auto-deformante que muda continuamente, a cada instante, ou como uma peneira cujas malhas mudassem de um ponto a outro." (DELEUZE, 1992, p. 221).

O principal objetivo da modulação digital não está em informar, mas em coletar dados. Para Zuboff (2021, p. 22), vivemos um capitalismo de vigilância que, através da internet e dos algoritmos de personalização, "[...] reivindica de maneira unilateral a experiência humana como matéria-prima gratuita para a tradução de dados comportamentais." Ao contrário das disciplinas que moldavam o corpo, as sociedades de controle modulam nossa mente (LAZZARATO, 2006; PARISER, 2012).

É fato que a internet, os algoritmos e as técnicas de Machine Learning nos trazem grandes vantagens, principalmente se considerarmos o volume de informação e dados disponíveis. Não podemos também supor que as tecnologias tenham relações de poder por si mesmas, as relações de poder, verdade e informação são humanas e a tecnologia é uma consequência que pode, sim, influenciar na manutenção ou revolução do status quo, afetando as subjetividades envolvidas em torno dessa tecnologia.

A partir das reflexões feitas até aqui sobre a utilização dos algoritmos nas formações discursivas e suas relações de poder, regimes de verdade e informação, seguimos para a descrição do percurso metodológico utilizado na elaboração da pesquisa, assim como seu tratamento, resultados, interpretações e análises acerca de como as Ciências Humanas e Sociais estão escrutinado a repercussão social dos algoritmos na contemporaneidade.

\section{PERCURSO METODOLÓGICO}

Considerando que os estudos acerca do papel social dos algoritmos digitais decorrem de uma temática recente ${ }^{5}$, optamos por classificar esta pesquisa como exploratória. A metodologia utilizada neste trabalho constitui-se em uma investigação de abordagem qualitativa pois, segundo Bardin (2016), é

\footnotetext{
5 Início da personalização de dados através de algoritmos na internet ocorreu por volta de 2009, segundo Pariser (2012).
} 
uma abordagem mais intuitiva, possibilitando a condução por categorias mais descritivas. Tal abordagem não exclui necessariamente a quantificação e pode, inclusive, utilizar-se de amostragens quantitativas, mas suas verdadeiras inferências são fundamentadas no significado, na representação temática e não apenas na frequência.

A Análise de Conteúdo (AC) foi escolhida como procedimento metodológico por ser um conjunto de técnicas de análise de comunicações, que conforme Laurence Bardin (2016), pode ser adaptada de acordo com a pesquisa realizada, permitindo tanto uma verificação prudente de seu conteúdo, quanto uma interpretação distinta, revelando seus significados e sua consistência. Sua aplicação ocorre em três momentos cronológicos: pré-análise, exploração do material e tratamento dos resultados.

Para atender ao objetivo desta pesquisa, realizamos a composição do corpus através de buscas nas bases de dados SCOPUS, SciELO e Project Muse. As referidas bases foram escolhidas devido às suas características e relevância no meio acadêmico. Inicialmente utilizamos os delimitadores: termo (algorithm or algorithms); temporalidade (2015 a 2019); ; área do conhecimento (Ciências humanas e sociais); tipologia de documento (artigos científicos); idioma (espanhol, inglês e português).

Iniciamos a pesquisa na base Scopus com os delimitadores mencionados e recuperamos 5189 documentos. Porém, para que fosse possível realizar uma análise qualitativa desses dados decidimos delimitar ainda mais a pesquisa, filtramos os termos 'algorithm or algorithms' no campo 'palavras-chave', recuperando assim 484 documentos. Na Base SciELO, utilizamos os mesmos delimitadores e a base retornou 172 artigos. Já a base de dados Project Muse entregou 32 trabalhos.

A partir do levantamento desses dados foi possível proceder com a etapa da pré-análise denominada por Bardin (2016) de "leitura flutuante". Assim sendo, efetuamos leituras técnicas (título, resumo, palavras-chave) com propósito de selecionar os documentos a serem categorizados, explorados e analisados.

\footnotetext{
${ }^{6}$ A presente pesquisa iniciou a análise dos dados em março de 2020 , portanto delimitamos a pesquisa para artigos publicados até o ano de 2019.
} 
Procedendo com a escolha dos documentos, primeiramente identificamos e excluímos as publicações repetidas, então selecionamos os artigos a serem analisados com base na regra de pertinência.

Como o objetivo que suscita esta análise está relacionado a função social do algoritmo, para selecionar os documentos pertinentes ao objeto deste trabalho desconsideramos as publicações com temáticas relacionadas a quantificação, racionalização, automação e software de maneira mais geral. Portanto, os artigos que explicam como desenvolver um algoritmo ou como implementar inteligência artificial para análises de resultados, sem discussões ou questionamentos sobre a questão social dos algoritmos, foram descartados. Após as ações realizadas na pré-análise, selecionamos 231 artigos.

Com o intuito de explorar os documentos e analisar seu conteúdo, nesta primeira etapa procuramos identificar a temática principal de cada estudo para agrupá-los por semelhança semântica. Segundo Bardin (2016), a categorização é um processo de classificação de elementos que pode ser semântico e se utilizar de categorias temáticas, possibilitando realizar testes durante a etapa da pré-análise com a finalidade de identificar possíveis dificuldades e realizar ajustes necessários em relação à pesquisa. Desta forma, com base na leitura do título, resumo e palavras-chave, identificamos inicialmente 17 pré-categorias.

A partir das escolhas e decisões estabelecidas durante a pré-análise, como a definição do corpus da pesquisa, a seleção de documentos e a escolha dos indicadores através das pré-categorias, chegamos à fase de Exploração do Material. Nesta etapa analisamos cada artigo individualmente, com leitura e interpretação de seu conteúdo a fim de identificar seu encaixe na regra de pertinência e então categorizá-lo. Neste momento descartamos 11 artigos que, apesar de conterem a expressão utilizada na busca (algorithm or algorithms) e terem passado no filtro da pré-análise, não trouxeram em seu conteúdo reflexões acerca do papel social dos algoritmos, como é o caso do artigo de Crompvoets, Béguin e Sijtsma (2019), intitulado "Adaptive Pairwise Comparison for Educational Measurement", que trata do desenvolvimento de um algoritmo a ser utilizado por profissionais da educação.

$A$ exploração do material também permitiu nos questionarmos quanto às 
pré-categorias já criadas. Com análise profunda dos trabalhos selecionados foi possível estabelecer relações entre as pré-categorias, possibilitando sua junção ou readequação de sua nomenclatura. Essas novas percepções resultaram em categorizações diferentes das pré-classificações que surgiram durante a préanálise. A leitura extensiva, o remanejo de artigos e novas nomenclaturas resultaram na exclusão de 6 categorias. Posto isso, com a exploração do material, classificamos 220 artigos em 11 categorias, conforme Figura 1.

\section{Figura 1 - Pré-categorias x Categorias}

\begin{tabular}{l}
\hline PRE-CATEGORIAS \\
\hline Algoritmos e policia \\
Algoritmos na educação \\
Algoritmos nas decisões judiciais \\
Algoritmos e as relações de trabalho \\
Algoritmos e cidadania \\
Algoritmos e direitos humanos \\
Algoritmos e memória \\
Algoritmos na comunicação \\
Controle e vigilância algoritmica \\
Cultura algoritmica \\
Discriminação algoritmica \\
Governabilidade algoritmica \\
Influência política dos algoritmos \\
Machine Learning \\
Personalização algoritmica \\
Poder e invisibilidade dos algoritmos \\
Regulaçãoe transparéncia dos algoritmos \\
\hline
\end{tabular}

\section{CATEGORIAS}

Algoritmos e as relações de trabalho

Algoritmos e jornalismo

Algoritmos e memória

Algoritmos na educação

Aprendizado de algoritmos (Machine learning)

Controle e vigilância algorítmica

Discriminação algoritmica

Governabilidade e governança algoritmica

Influência politica dos algoritmos

Personalização algorítmica

Regulamentação e transparência dos algoritmos

Fonte: dados da pesquisa, 2020. Autora, 2021

A redução do número de categorias, suas nomenclaturas e a classificação dos artigos, ocorreu com base em inferências e interpretações. Como por exemplo o caso das pré-categorias "Cultura algorítmica" e "Personalização algorítmica". Ambas foram fundidas em razão de compreendermos, a partir do aprofundamento da leitura, que ambos conceitos se conciliam. Mas, devido à expressão "personalização algorítmica" ser mais utilizada nos artigos coletados, optamos por deixá-la na denominação da categoria.

A categorização buscou traçar limites, por vezes tênues, entre as temáticas (BARDIN, 2016). Portanto, a classificação que propomos não exclui a possibilidade dos artigos agrupados abordarem assuntos de outras categorias, mas ao categorizarmos nos baseamos no enfoque de cada trabalho e sua temática, estando mais voltado a alguns temas do que a outros, segundo nossa perspectiva. Não tivemos a pretensão de criar conceitos, pois esta elaboração 
exigiria aquisição de múltiplas informações, conhecimentos e saberes que resultariam em outra pesquisa. A nomenclatura das categorias ocorreu apenas por identificação de seu assunto principal e não fazem distinção entre efeitos e campos de estudo. A categorização dos artigos emerge dos dados da análise temática independentemente da quantidade, pois consideramos como requisito de classificação os assuntos identificados.

Desta forma chegamos às 11 categorias temáticas em que os 220 trabalhos que fazem parte do corpus desta pesquisa foram agrupados, possibilitando a realização da última etapa da $\mathrm{AC}$, o tratamento dos resultados, inferências e sua interpretação que serão apresentados na próxima seção.

\section{RESULTADOS E ANÁLISES}

Analisamos 220 artigos científicos que trazem em seu conteúdo reflexões acerca dos algoritmos como preocupação social. Percebemos, pelos estudos acadêmicos analisados, que a temática vem sendo mais debatida, embora haja oscilações em relação ao número de publicações por período (Quadro 1). Os anos que apresentaram maior número de artigos publicados foram 2019, 2018 e 2016 , representando $36 \%$, $21 \%$ e $20 \%$ do corpus analisado, respectivamente. Enquanto os anos de 2017 e 2015 apresentaram menor número de publicações, representando $12 \%$ e $10 \%$, nesta ordem.

\section{Quadro 1 - Frequência de artigos por categoria e por ano}

\begin{tabular}{|l|r|r|r|r|r|r|}
\hline \multicolumn{1}{|c|}{ Categorias } & $\mathbf{2 0 1 5}$ & $\mathbf{2 0 1 6}$ & $\mathbf{2 0 1 7}$ & $\mathbf{2 0 1 8}$ & $\mathbf{2 0 1 9}$ & Total \\
\hline Personalização algorítmica & 8 & 13 & 7 & 15 & 13 & 56 \\
\hline Controle e vigilância algorítmica & 2 & 9 & 3 & 7 & 12 & 33 \\
\hline Regulamentação e transparência dos algoritmos & 1 & 6 & 3 & 5 & 12 & 27 \\
\hline Algoritmos e jornalismo & 2 & 5 & 5 & 4 & 10 & 26 \\
\hline Discriminação algorítmica & 2 & 6 & 1 & 2 & 9 & 20 \\
\hline Governabilidade e governança algorítmica & 3 & 3 & 1 & 4 & 9 & 20 \\
\hline Algoritmos e as relaç̋̃es de trabalho & 1 & 0 & 2 & 1 & 6 & 10 \\
\hline Influência política dos algoritmos & 0 & 1 & 2 & 4 & 3 & 10 \\
\hline Algoritmos na educação & 1 & 2 & 3 & 2 & 1 & 9 \\
\hline Aprendizado de algoritmos (Machine learning) & 0 & 0 & 0 & 2 & 5 & 7 \\
\hline Algoritmos e memória & 1 & 0 & 0 & 1 & 0 & 2 \\
\hline Grand Total & $\mathbf{2 1}$ & $\mathbf{4 5}$ & $\mathbf{2 7}$ & $\mathbf{4 7}$ & $\mathbf{8 0}$ & $\mathbf{2 2 0}$ \\
\hline
\end{tabular}

Fonte: dados da pesquisa, 2020. Autora, 2021 
Relacionamos como um dos fatores contribuintes para o crescimento de publicações no ano de 2016 a repercussão do caso Snowden, cujo filme estreou naquele ano (SNOWDEN, 2016). O filme conta a história do analista norteamericano Edward Snowden e relata o amplo monitoramento do governo daquele país sobre vários outros, através da utilização de servidores como os do Google e do Facebook. Em 2018 e, principalmente, 2019 também houve aumento de produções sobre o tema. Neste período ocorreu o vazamento sobre a violação de dados de mais de 50 milhões de pessoas, utilizados sem consentimento pela empresa Cambridge Analytica (ENTENDA..., 2018). A empresa foi denunciada por utilizar dados coletados para interferir nas eleições norte-americanas de forma favorável ao então candidato Donald Trump e a favor da saída do Reino Unido da União Europeia nas eleições sobre o Brexit.

A utilização de servidores do Google e do Facebook para vigilância, como no caso denunciado por Edward Snowden e na coleta indevida de dados utilizados pela Cambridge Analytica para influenciar eleições, está diretamente relacionada aos algoritmos, pois é através deles que a coleta e o processamento de dados acontecem. Os fatos ocorridos alertaram sobre a possibilidade das indicações algorítmicas influenciarem o comportamento humano através de recomendações manipuláveis, pois os algoritmos não são máquinas abstratas, há em seus bastidores escolhas humanas e institucionais (GILLESPIE, 2018). Situações como as relatadas despertam curiosidades e apreensões sobre 0 papel social dos algoritmos em vários aspectos.

A partir da análise e leitura dos artigos analisados, agrupamos os trabalhos por semelhança temática para melhor explorá-los. A organização dos artigos em categorias possibilitou análise sobre quais são os principais temas abordados dentro dos estudos acadêmicos, aqui representados pelos artigos científicos, nas áreas das Ciências Sociais e Humanas em relação aos algoritmos como preocupação social. Embora algumas categorias possuam um número elevado de artigos, como fica evidente no Quadro 1, a categorização dos artigos emergiu dos dados da análise temática independentemente da quantidade, pois consideramos como requisito de classificação os assuntos identificados. Nos próximos parágrafos apresentamos breve análise sobre cada 
categoria com vistas a elucidar as temáticas para posteriores reflexões e considerações.

Identificamos (Quadro 1) que os picos de produção sobre a categoria Personalização Algorítmica estão nos anos de 2016, 2018 e 2019. Este assunto foi o mais recorrente no material analisado, representando $25 \%$ dos artigos coletados. Dentro dessa categoria identificamos 56 artigos que em sua composição tratam de assuntos relacionados à personalização de conteúdos na internet e seus impactos nas sociedades.

Analisando o conteúdo dos artigos selecionados nesta categoria percebemos que, apesar da agregação dentro de um contexto de personalização algorítmica, os autores apresentam múltiplas reflexões sobre o tema. Em sua maioria os artigos selecionados questionam as consequências de deixarmos os algoritmos influenciarem nossas decisões, desde uso para entretenimento até consumo de notícias e reprodução de comportamento, refletindo acerca do desconhecimento por parte dos usuários comuns sobre o funcionamento da personalização algorítmica. Existe também a preocupação por parte dos autores com bolhas dos filtros, que se tornam cada vez mais densas, construindo sociedades cada vez mais fechadas, tão absortas por essa personalização algorítmica que não consigam perceber possíveis manipulações nas recomendações recebidas. De modo geral, percebemos o reconhecimento por parte dos autores de que a personalização algorítmica não é neutra, podendo atuar como agente político, cultural e social.

Os artigos selecionados para a categoria Controle e Vigilância Algorítmica abordam as formas de vigilância (coleta de dados, monitoramento de informações) e de controle (tomada de decisões, alteração de comportamento, gerenciamento de acessos) desses sistemas automatizados. Ao todo, classificamos 33 trabalhos, $15 \%$ do total de artigos selecionados. Assim como observado no panorama geral dos artigos selecionados, houve picos de produção sobre a temática, tanto no ano de 2016, quanto no ano de 2019.

A percepção sobre o fator humano e social por trás da máquina também aparece nos artigos desta categoria, que trazem em sua discussão a privatização da vigilância. Os autores alertam que são poucas as empresas que detêm o 
poder de controlar e programar os algoritmos, o que nos leva ao conceito de capitalismo de vigilância, que através da mercantilização dos dados propicia a vigilância e controle algoritmos mais voltados para o consumo e para o marketing (DELEUZE, 1992). O excesso de confiança e dependência dos usuários nos dispositivos digitais também ampliam o acesso aos dados coletados e a ignorância sobre seu funcionamento e suas diretrizes, fazem com que a vigilância seja discreta e o controle seja disfarçado de sugestão.

Os 27 artigos que compõem a categoria Regulamentação e Transparência dos Algoritmos, representam 12\% do corpus. Observamos que novamente o ano de 2019 foi o maior em número publicações com essa temática, demonstrando que este debate é uma preocupação atual. Os artigos classificados nessa categoria trazem ao debate a questão da opacidade nos processos de tomadas de decisão algorítmica e os crescentes desafios para regulamentar algoritmos. Os autores apresentam sugestões de como regulamentar, se não diretamente os algoritmos, então as organizações responsáveis pelo seu desenvolvimento, limitando a extensão dos poderes algoritmos através de recursos legais que atentem ao menos para a privacidade e proteção de dados.

A falta de transparência no desenvolvimento e aplicação algorítmica é mencionada em quase todas as categorias apresentadas, porém, foram nos artigos aqui agrupados que identificamos esta temática de maneira mais analítica. Os estudos apresentados trouxeram exemplos de regulamentação algorítmica com as leis norte-americanas e europeias. O entendimento de que as leis de proteção de dados, transparência e regulamentação algorítmica ainda estão em processo de debate e construção é unânime por parte dos artigos selecionados nesta categoria. Em sua maioria, os trabalhos trazem à discussão a possibilidade de regulamentação e transparência, considerando as dificuldades técnicas e a dinâmica nas relações algorítmicas. Os autores acreditam que cada país, cada sociedade deve analisar suas questões de automatização e regulamentação dessas atividades.

$\mathrm{Na}$ categoria Algoritmos e Jornalismo identificamos 26 artigos que dissertam sobre as consequências, influências da programação e a 
automatização da mediação nos processos de comunicação digital, principalmente no trabalho dos jornalistas. Foram 23 artigos no idioma inglês, 2 em espanhol e 1 em português. $O$ ano de 2019 teve o maior volume de publicações com essa temática. A crescente atenção com este tópico provavelmente está relacionada com o aumento da utilização de mídias digitais para o consumo de notícias e o consequente interesse nos estudos do que acontece nessas plataformas.

Os jornalistas admitem que a crescente utilização dos algoritmos influencia na realização do seu trabalho, contudo esses profissionais não se sentem intimidados com as tecnologias, percebendo-a como aliada, desde que tratada e utilizada com responsabilidade ética. A preocupação com a forma como os consumidores de notícias entendem, utilizam e compartilham notícias nas plataformas digitais também se faz presente nos artigos.

A utilização de tecnologias nas tomadas de decisões governamentais é progressiva. Na categoria denominada Governabilidade e Governança Algorítmica os autores trazem pensamentos e repercussões acerca das implicações no uso de algoritmos nas funções governamentais. A comunicação entre população e governo, prestação de contas, formas de vigilância e transparência também são assuntos que os artigos selecionados para a categoria abordam. Ao todo, identificamos 20 artigos que trazem esta temática.

Os estudos agrupados nesta categoria reconhecem que a utilização de sistemas bem desenvolvidos pode auxiliar na governança, porém é recorrente a preocupação dos autores com 0 desenvolvimento desses sistemas, principalmente quanto à opacidade dos algoritmos. Ainda que amplamente utilizados para tomadas de decisões, muitas vezes seus usuários, neste caso os agentes políticos e funcionários públicos, não compreendem totalmente a forma como um algoritmo chega a um resultado. A alimentação das bases de dados com informações corretas e a interpretação dos resultados são os principais desafios na esfera pública, por isso os autores alertam para a necessidade de análise crítica sobre os sistemas automatizados para tomada de decisões, com constante regulamentação, observação e participação de todos os envolvidos na utilização desses sistemas. 
Muito além da simples recomendação de conteúdo e análises de resultados, a utilização de algoritmos pode levar a perpetuação de preconceitos. A discriminação algorítmica está envolta em casos de invisibilidade na rede (determinados grupos não serem reconhecíveis pelos algoritmos) ou pela manutenção de estereótipos e preconceitos relacionados a esses indivíduos. Logo, os 20 estudos agrupados na categoria Discriminação Algorítmica apresentam reflexões específicas acerca dos indivíduos ou grupos de indivíduos discriminados por qualquer conteúdo digital.

As pesquisas elencadas nesta categoria alertam para 0 fato dos algoritmos tomarem decisões sobre o futuro com base em estatísticas e captação de padrões. Todavia, assim como afirmam Sandvig, Hamilton, Karahalios e Langbort (2016), o algoritmo per se não é discriminatório, seu aprendizado advém de bases de dados e exemplos, logo, a utilização de padrões históricos e sociais utilizados pelos algoritmos podem estar relacionados à representação desproporcional dos indivíduos ou de grupos de indivíduos. Constatamos novamente a preponderância de olhares sobre a aparente neutralidade dos algoritmos e como isso pode prejudicar a criticidade sobre as diretrizes e parametrizações utilizadas em suas programações. É também recorrente a preocupação sobre a representação de padrões sociais que se ampliam dentro da web, muitas vezes de forma despercebida, mas que naturalizam determinados preconceitos e discriminações.

Assim como a utilização de algoritmos vem acarretando transformações na forma como nos conectamos, consumimos produtos, notícias e entretenimento, esses dispositivos também alteram as relações de trabalho. A categoria Algoritmos e as Relações de Trabalho é composta por 10 artigos, 9 no idioma inglês e 1 no idioma português, que debatem sobre as relações entre o trabalho e os algoritmos.

Os artigos apresentam perspectivas críticas sobre as novas relações trabalhistas, no qual novas formas de exploração típicas do capitalismo são favorecidas pelos algoritmos, proporcionando certa emancipação das empresas de uma direção pessoal de trabalho, pois agora quem assume este papel é um algoritmo. Os autores também apresentam preocupação sobre os direitos e 
garantias dos trabalhadores, com um discurso de aparente autonomia e flexibilidade as empresas se isentam de vínculos trabalhistas, aumentando a precarização do trabalho com extensas jornadas, baixa remuneração, poucas garantias e direitos, muito semelhante aos primórdios do capitalismo. Os autores ainda destacam a necessidade de regulamentar essas novas relações trabalhistas, garantindo um mínimo de dignidade e segurança aos trabalhadores.

A categoria Influência Política dos Algoritmos apresenta 10 artigos que trazem à discussão a interferência dos algoritmos nas escolhas políticas, tanto no sentido social quanto em escolhas partidárias, principalmente na utilização das mídias sociais digitais. A abordagem neoliberal das mídias digitais tem como propósito principal garantir lucro através de engajamento, no qual números de acessos e curtidas tornam-se mais relevantes do que o conteúdo e a veracidade das informações. Os autores mostram preocupação quanto à manipulação das redes sociais digitais em relação a polarização política, desfavorecendo o debate democrático e contribuindo para o autoritarismo e o populismo.

O alcance dos algoritmos ultrapassa as mídias digitais, pois, com a internet, as informações podem ser obtidas a qualquer hora e em qualquer lugar, transformando radicalmente as relações entre professores e alunos. A categoria Algoritmos na Educação contém 9 artigos que apresentam reflexões acerca de como os algoritmos estão alterando a prática educacional, bem como a forma de aprender. Os autores afirmam que a presença do professor e da professora, justamente por causa da cultura digital, é cada vez mais necessária, pois eles seriam os mediadores conceituais, analisando criticamente as informações coletadas na internet, questionando sua pretensa neutralidade, proporcionando a verdadeira aquisição de conhecimento de forma crítica. A análise crítica em relação a utilização dos algoritmos está presente na maioria dos artigos aqui analisados, demonstrando a necessidade de maior transparência na utilização desses sistemas automatizados, inclusive na área educacional, ficando evidente que há necessidade de capacitar e desenvolver educadores e demais profissionais da área da educação para analisar a utilização de sistemas digitais.

Os 7 artigos elencados na categoria Aprendizado de algoritmos abordam a percepção dos algoritmos sobre o ângulo de aprendizagem de 
máquinas (machine learning), suas ramificações como deep learning (aprendizagem profunda) e as redes neurais de aprendizado e seus dilemas éticos. Localizamos apenas publicações dos anos de 2018 e 2019 com essa temática de forma específica, o que sugere que o assunto sobre o aprendizado dos algoritmos e seus impactos sociais ainda está em construção, possivelmente por sua aplicação ser mais recente. Percebemos a preocupação dos autores em esclarecer que os algoritmos, inclusive os utilizados no aprendizado de máquina, não são neutros, mas um reflexo das sociedades e contextos aos quais fazem parte, portanto devem ser analisados sob a ótica da ética, suscitando em discussões filosóficas, políticas e sociais a respeito da utilização desses sistemas e seus impactos nas nossas sociedades.

A categoria Algoritmos e memória foi criada a partir da identificação dos artigos que, embora tragam questões sobre transparência dos algoritmos e personalização algorítmica, abordam especificamente suas influências na construção das memórias. Selecionamos para essa categoria 2 artigos que acrescentam ao debate sobre os algoritmos a questão da memória, um publicado em 2015 e outro em 2018. Os autores sinalizam que o esquecimento e as diferentes narrativas dos acontecimentos virais na internet modulam a construção das memórias e, por consequência, a construção como sujeito, individual ou coletivamente. Os dois artigos classificados nesta categoria refletem sobre a personalização algorítmica na construção das memórias através dos filtros de seleção e compartilhamento de conteúdos com base nas estruturas das plataformas utilizadas, bem como suas políticas, opacidade dos algoritmos e sua influência supostamente neutra na memória, tanto coletiva quanto na memória individual.

Os estudos analisados em todas as categorias trazem diferentes questionamentos e reflexões acerca dos múltiplos universos que envolvem a influência dos algoritmos. A influência algorítmica não acontece somente na hora de tomarmos decisões simples ao consumir produtos e conteúdos; os dispositivos estão presentes em manipulações de comportamento muito mais complexas. As decisões algorítmicas baseadas em estatísticas e padrões, por estarem vinculadas aos grupos economicamente dominantes, acabam por 
reproduzir padrões históricos e sociais.

Embora a personalização algorítmica seja a categoria com maior número de artigos selecionados, o desconhecimento por parte dos usuários sobre 0 funcionamento dos algoritmos é tema frequente nos estudos acadêmicos analisados nesta pesquisa, sendo mencionado em diversas categorias com olhares e preocupações divergentes. Mas, ainda que a falta de transparência seja recorrente nos trabalhos analisados, as pesquisas reconhecem que a transparência não é a única solução para as demandas de responsabilidade, pois além de questões técnicas sobre o desenvolvimento dos algoritmos, existem questões legais e comerciais. O principal desafio ainda está em desvincular o poder dos algoritmos das poucas e poderosas empresas responsáveis pelo seu desenvolvimento, para que então as tecnologias possam atender as necessidades reais da sociedade.

A percepção de que a tecnologia não é neutra aparece frequentemente nos artigos analisados, aquiescendo às percepções de Foucault (1979; 2000) e González de Gómez (1999; 2019) sobre as conduções, coerções e incitações econômicas por trás dos regimes de verdade e de informação. As decisões algorítmicas desempenham papéis de agentes políticos, sociais e culturais sendo influenciadas e influenciando essas relações. A construção da vontade da verdade é inerente às relações de poder, que, por sua vez, modifica-se de acordo com a complexidade de cada sociedade. Embora não exista poder totalmente dominante, a vontade da verdade, os regimes de verdade e de informação tendem a ser subservientes à ordem discursiva dominante (FOUCAULT, 1979; GONZÁLEZ DE GÓMEZ, 1999; KHOSRAVINIK, 2018).

Os artigos analisados constatam que a tecnologia pode ser aliada no desenvolvimento de uma sociedade mais justa e democrática, desde que utilizada e desenvolvida com responsabilidade ética. Porém, reconhecem que os algoritmos ecoam as estruturas normativas de cada sociedade e, em uma sociedade neoliberal, são organizados em volta de uma perspectiva comercial (KHOSRAVINIK, 2018; VIANA, 2018; BORGES; GAMBARATO, 2019; VILLAGRASA, 2019; ZUBOFF, 2021).

Os trabalhos analisados nas categorias trazem reflexões sobre as 
consequências do uso excessivo das customizações algorítmicas na manipulação de informações, através da segmentação de conteúdo aos usuários. Os autores alertam que, apesar da opacidade, a utilização de serviços digitais cria relações de confiança e dependência entre os usuários e esses dispositivos, facilitando a manipulação de informações decorrente das influências algorítmicas, alterando a percepção sobre as informações acessadas e compartilhadas, privatizando processos informacionais (STRIPHAS, 2015). Diferentemente da sociedade disciplinar existente no capitalismo industrial, o novo capitalismo não está mais voltado para produção, mas sim para o consumo. Com a contribuição dos algoritmos, não controla apenas corpos, mas, fluxos e ideias através de modulações próprias da Sociedade de Controle.

\section{CONSIDERAÇÕES FINAIS}

Os artigos coletados trazem em seu escopo a preocupação social do uso dos algoritmos digitais sob diferentes perspectivas. Utilizando como procedimento a Análise de Conteúdo, com vistas a atender o objetivo deste trabalho, analisamos 220 artigos científicos. O recente crescimento no número de pesquisas voltadas à temática dos algoritmos como preocupação social é perceptível e justificável ao considerarmos o fato dos algoritmos estarem cada vez mais presentes no nosso cotidiano.

Os artigos analisados foram classificados em 11 diferentes categorias, por agrupamento semântico. Ao estabelecermos as relações existentes entre as categorias analisadas percebemos que as temáticas de personalização, controle, vigilância, regulamentação e transparência dos algoritmos são recorrentes entre os questionamentos dos autores dos trabalhos analisados. Tais temas também são congruentes, pois, ainda que haja categorização, constatamos preocupação por parte dos autores sobre as consequências da utilização de algoritmos para tomadas de decisões, desde as mais simples, como consumo de produtos até questões complexas como decisões políticas e sociais. A falta de transparência quanto ao desenvolvimento e aplicação desses dispositivos, bem como o desconhecimento por parte dos usuários, tanto das questões técnicas quanto das questões legais, são temas assíduos nos artigos 
analisados.

Continuamente os artigos afirmam que a tecnologia não é neutra, embora esta seja aparente, proporcionando aos usuários a ilusão de controle sobre aquilo que é consumido. Mesmo nos casos de aprendizado de máquina e sistemas neurais artificiais para a implementação de inteligência artificial, a responsabilidade ética no desenvolvimento dessas tecnologias é mencionada. Além da responsabilidade ética, os artigos reforçam que os algoritmos refletem e reproduzem as formações discursivas de cada sociedade.

Os autores dos trabalhos analisados explicam que os algoritmos não buscam apenas oferecer conteúdo, buscam engajamento, por isso fazem recomendações. Tais recomendações são alicerçadas nos próprios interesses das plataformas digitais, se estendendo além das preferências de consumo e existindo em diversas esferas econômicas, tanto públicas, quanto privadas, sendo políticas e sociais. Os benefícios dos algoritmos não são descartados nos estudos, mas quando os utilizamos sem pensamento crítico, acabamos por reforçar padrões que beneficiam apenas a parcela com maior poder dominante e, em uma sociedade capitalista, é o poderio econômico que propicia o controle, facilitando que os algoritmos sirvam como mecanismos de manutenção desse poder.

As reflexões e questionamentos sobre os algoritmos digitais como preocupação social ainda carecem de mais estudos e, com o avanço das tecnologias, mais dúvidas e debates vão surgir. Como as novas tecnologias influenciam no desenvolvimento das sociedades e são influenciadas por elas, as Ciências Humanas e Sociais buscando compreender esses fenômenos e suas consequências tendem a pesquisar cada vez mais esse fenômeno.

Pelo caráter exploratório, em nossa pesquisa anunciamos possibilidades de investigação e exploração de elementos que podem ser identificados a partir dos resultados da investigação e análise do corpus feita até aqui. Acreditamos que a variedade de temas abordados nesta pesquisa possa contribuir para futuras pesquisas em diversas áreas do conhecimento. A partir de cada categoria podem surgir novas pesquisas que aprofundem nossa investigação e tragam novos debates acerca desta temática. 


\section{REFERÊNCIAS}

BARDIN, L. Análise de Conteúdo. Lisboa: Edições 70, 2016.

BERT, J.-F. Pensar com Michel Foucault. São Paulo: Parábola, 2013.

BORGES, P. M.; GAMBARATO, R. R. The role of beliefs and behavior on facebook: a semiotic approach to algorithms, fake news, and transmedia journalism. International Journal of Communication, v. 13, p. 16, 2019.

CARRERA, F. Racismo e sexismo em bancos de imagens digitais: análise de resultados de busca e atribuição de relevância na dimensão financeira/profissional. In: SILVA, T. (org.). Comunidades, algoritmos e ativismos digitais: Olhares afrodiaspóricos. São Paulo: LiteraRUA, 2020. cap. 8.

CORMEN, T. H. Desmistificando algoritmos. Elsevier Brasil, 2014.

CROMPVOETS, E. A. V.; BÉGUIN, A. A.; SIJTSMA, K. Adaptive Pairwise Comparison for Educational Measurement. Journal of Educational and Behavioral Statistics, v. 45, n. 3, 2019.

DARDOT, P.; LAVAL, C. A nova razão do mundo: ensaio sobre a sociedade neoliberal. São Paulo: Boitempo, 2016.

DELEUZE, G. Conversações. São Paulo: Ed. 34, 1992.

ENTENDA o escândalo de uso político de dados que derrubou valor do Facebook e o colocou na mira de autoridades. BBC News, 20 março de 2018, Internacional. Disponível em: https://www.bbc.com/portuguese/internacional43461751. Acesso em: 28 dez. 2021.

FOUCAULT, M. Microfísica do poder. 13. ed. Rio de Janeiro: Graal, 1979. $296 \mathrm{p}$.

FOUCAULT, M. Ordem do discurso (A). Edições Loyola, 1996.

FOUCAULT, M. Em Defesa da Sociedade. São Paulo: Martins Fonte, 2000.

FOUCAULT, M. Poder e Saber. In: MOTTA, M. B. da (org.). Estratégia, podersaber. Rio de Janeiro: Forense/Universitária, 2006. Coleção Ditos \& Escritos, v. 4, p. 223-240.

FROHMANN, B. Taking information policy beyond information science: applying the actor network theory. In: ANNUAL CONFERENCE: CANADIAN ASSOCIATION FOR INFORMATION, 23., 1995. Proceedings [...]. Edmonton, Alberta: CAIS/ACSI, 1995. 
GILLESPIE, T. Algorithmically recognizable: Santorum's Google problem, and Google's Santorum problem. Information, communication \& society, v. 20, n. 1, p. 63-80, 2017.

GILLESPIE, T. A relevância dos algoritmos. Parágrafo, v. 6, n. 1, p. 95-121, 2018.

GLEICK, J. Informação: Uma história, uma teoria, uma enxurrada. Lisboa: Círculo de Leitores, 2012.

GONZÁLEZ DE GÓMEZ, M. N. O caráter seletivo das ações de informação. Informare, Rio de Janeiro, v. 5, n. 2, p. 7-31, 1999.

GONZÁLEZ DE GÓMEZ, M. N. Reflexões Sobre a genealogia dos regimes de informação. Informação e Sociedade: Estudos, João Pessoa, v. 29, n. 1, p. 137-158, jan./mar. 2019.

KHOSRAVINIK, M. Social media techno-discursive design, affective communication and contemporary politics. Fudan Journal of the Humanities and Social Sciences, v. 11, n. 4, p. 427-442, 2018.

LAZZARATO, Maurizio. As revoluções do capitalismo. Rio de Janeiro: Civilização Brasileira, 2006.

MEDEIROS, J. Compreensões sobre o dispositivo: da informação à via para profanação. Informação \& Informação, Londrina, v. 22, n. 3, p. 158-177, set./out. 2017.

OLIVEIRA, C. Aprendizado de máquina e modulação do comportamento humano. In: SOUZA, J.; AVELINO, R.; SILVEIRA, S. A. (org.) A sociedade de controle: Manipulação e modulação nas redes digitais. São Paulo: Hedra, 2018. p. 31-46.

PARISER, E. O filtro invisível: o que a internet está escondendo de você. Rio de Janeiro: Zahar, 2012.

PASQUALE, F. The black box society. Harvard University Press, 2015.

REVEL, J. Foucault: conceitos essenciais. São Carlos: Clara Luz, 2005.

SANDVIG C.; HAMILTON K.; KARAHALIOS, K.; LANGBORT, C. Automation, algorithms, and politics| when the algorithm itself is a racist: Diagnosing ethical harm in the basic components of software. International Journal of

Communication, v. 10, p. 19, 2016. 
SNOWDEN. Direção: Oliver Stone. Produção: Moritz Borman; Eric Kopeloff; Philip Schulz-Deyle; Fernando Sulichin. Empresa Produtora: Endgame Entertainment; Wild Bunch; KrautPack Entertainment; Onda Entertainment; Vendian Entertainment, 2016.

STRIPHAS, T. Algorithmic culture. European Journal of Cultural Studies, v. 18, n. 4-5, p. 395-412, 2015.

VIANA, B. O Jornalismo no contexto da Web Semântica. Media \& Jornalismo, Lisboa, v. 18, n. 32, p. 187-199, 2018.

VILLAGRASA, O. C. Las herramientas inteligentes anticorrupción: entre la aventura tecnológica y el orden jurídico. Revista General de Derecho Administrativo, n. 50, p. 34, 2019.

ZUBOFF, S. A era do capitalismo de vigilância: a luta por um futuro humano na nova fronteira do poder. Rio de Janeiro: Editora Intrínseca, 2021.

\title{
SOCIAL ROLE OF ALGORITHMS: AN ANALYSIS OF ACADEMIC STUDIES ABOUT THE DIGITAL ALGORITHMS SUCH AS SOCIAL CONCERN.
}

\begin{abstract}
Objective: to analyze how the academic studies, presented in scientific articles, constitute about the digital algorithms such as social concern, in the areas of Social Sciences and Humanities, through Project Muse databases, SCOPUS and SciELO. Methodology: This paper use exploratory and qualitative and it uses the methodological procedures of Content Analysis, carried out in three stages (pre-analysis, exploration of the material and treatment of the data) for the survey and analysis of the documents collected in the databases. Results: From the survey in the databases, it analyzes 220 selected scientific articles, which bring in their content reflections on the social role of algorithms. Classifies the analyzed articles into 11 categories, grouped by thematic similarity. Conclusions: Concludes that the theme with the greatest representation among the analyzed articles related to algorithmic customization, together with reflections on opacity, manipulation and algorithmic discrimination, their impacts and influence on human behavior. Understand that the algorithms are not neutral, but reflect and reproduce the discursive formations of each society. Perceives that the reflections and questions about the social role of the algorithms still need research. Announces perspectives for new studies based on the results and investigations present in this research.
\end{abstract}

Descriptors: Algorithms. Content analysis. Regimes of truth. Regimes of information. Control society. 


\section{PAPEL SOCIAL DE LOS ALGORITMOS: ANÁLISIS DE ESTUDIOS ACADÉMICOS SOBRE ALGORITMOS Y SU FUNCIÓN SOCIAL.}

\section{RESUMEN}

Objetivo: analizar cómo se constituyen los estudios académicos, presentados en artículos científicos, sobre los algoritmos digitales como una preocupación social, en las áreas de Ciencias Sociales y Humanas, a través de las bases de datos Project Muse, SCOPUS y SciELO. Metodología: Con carácter exploratorio y enfoque cualitativo, esta investigación utiliza los procedimientos metodológicos del Análisis de Contenido, realizado en tres etapas (preanálisis, exploración de materiales y procesamiento de datos). Resultados: A partir de la encuesta en estas bases de datos, analiza los 220 artículos científicos seleccionados, que aportan en su contenido reflexiones sobre el papel social de los algoritmos. Clasifica los artículos analizados en 11 categorías, agrupadas por similitud temática. Conclusiones: Se concluye que el tema con mayor representación entre los artículos analizados está relacionado con la personalización algorítmica, junto con las reflexiones sobre la opacidad algorítmica, manipulación y discriminación, sus impactos e influencia en el comportamiento humano. Entiende que los algoritmos no son neutrales, sino que reflejan y reproducen las formaciones discursivas de cada sociedad. Entiende que las reflexiones y preguntas sobre el papel social de los algoritmos aún carecen de investigación. Anuncia perspectivas para nuevos estudios basados en los resultados e investigaciones presentes en esta investigación.

Descriptores: Algoritmos. Análisis de contenido. Regímenes de verdad. Regímenes de información. Sociedad del control.

Recebido em: 08.09.2021

Aceito em: 17.12.2021 